\title{
Carrageenophytes of occidental Portuguese coast: 1-spectroscopic analysis in eight carrageenophytes from Buarcos bay
}

\author{
Leonel Pereira*, José F. Mesquita \\ Laboratory of E.M. and Phycology, Botany Department, University of Coimbra, 3000 Coimbra, Portugal
}

\begin{abstract}
Infrared and Raman spectroscopic analysis of the carrageenan (alkaline extraction) in eight species (representing seven genera and four families) of Gigartinales, in different reproductive phases from Buarcos bay (Figueira da Foz, Portugal), were studied. Female gametophytes and non-fertile thalli samples of Chondrus crispus, Mastocarpus stellatus, Chondracanthus teedei var. lusitanicus, Gigartina pistillata and Chondracanthus acicularis present a $\kappa$-carrageenan profile or varying degrees of a $\kappa-1$ hybrid. The presence of $\kappa-1$ hybrid carrageenan in C. teedei var. lusitanicus was confirmed by ${ }^{13} \mathrm{C}$ NMR. The carrageenans extracted from Gymnogongrus crenulatus and Ahnfeltiopsis devoniensis are constituted mainly by -carrageenan but seasonal variations in the nature of carrageenans are present. $\lambda$-Family carrageenans were found in tetrasporophytes of C. crispus, M. stellatus, C. teedei var. lusitanicus, C. acicularis and G. pistillata. Calliblepharis jubata presents carrageenans of t-type in all reproductive stages.
\end{abstract}

(C) 2003 Elsevier Science B.V. All rights reserved.

Keywords: Portugal; Carrageenophytes; Carrageenan; FTIR; FT-Raman; ${ }^{13} \mathrm{C}$ NMR

\section{Introduction}

The carrageenophytes pertaining to the Gigartinaceae, Petrocelidaceae, Phyllophoraceae and Cystocloniaceae families (Gigartinales, Rhodophyta) are widely distributed in the Atlantic centre and north coast of Portugal. However, Mastocarpus stellatus (Petrocelidaceae) and Chondrus crispus (Gigartinaceae) are the only species currently harvested for industrial aims, mainly in the north coast (Viana do Castelo) (personal observation).

Carrageenan is a structural cell wall component constituted by sulphated polysaccharides (galactans), which can form gels in water or milk solutions. This phycocolloid is used mainly in cosmetic, pharmaceutical and food industry [1].

The $\kappa$-carrageenan and the hybrid forms $(\kappa-1)$ occur normally in Gigartinaceae and Petrocelidaceae gametophytes; the $\lambda$-family carrageenans appear habitually in the tetrasporophytic stages [2]. Finally, the 1-carragee-

\footnotetext{
* Corresponding author. Tel.: +351-239-822-897; fax: +351-239820-780.

E-mail address: leonel@ci.uc.pt (L. Pereira).
}

nan (and $1-\kappa$ hybrids) is produced mainly by species of the genus Eucheuma (Eucheuma denticulatum) and also by some other species of the Cystocloniaceae and Phyllophoraceae families [2,3].

\section{Materials and methods}

Samples of all eight studied carrageenophytes were collected randomly in the intertidal zone, at different times (Table 1), in Buarcos Bay (Figueira da Foz, Portugal). The seaweeds were collected by hand at low tide and washed with distillate freshwater to eliminate salt, debris and contaminants. The material was separated, whenever possible, into three groups (female gametophytes, tetrasporophytes and non-fertile thalli) and dried to constant weight at $60{ }^{\circ} \mathrm{C}$.

The procedure for carrageenan extraction (alkaline extraction) has been previously outlined [4].

The carrageenan samples have been analysed by FTIR, FT-Raman (only for the $\lambda$-family carrageenans) and ${ }^{13} \mathrm{C}$ NMR (only for the $\kappa-1$ hybrid samples) spectroscopy.

The FTIR spectra were recorded on an IFS 55 spectrometer, using a Golden Gate single reflection 
Table 1

Species, reproductive stages, sampling dates and carrageenan type

\begin{tabular}{|c|c|c|c|c|}
\hline Code & Species & Stages & Dates & Carrageenan type \\
\hline A & C. crispus Stackhouse & NF & December 2000 & $\kappa$ \\
\hline $\mathrm{B}$ & C. crispus Stackhouse & FG & February 2001 & $\kappa$ \\
\hline $\mathrm{C}$ & M. stellatus (Stackhouse) Guiry & G & August 2001 & $\kappa$ \\
\hline $\mathrm{D}$ & G. pistillata (S.G. Gmelin) Stackhouse & FG & March 2002 & $\kappa(1)$ \\
\hline $\mathrm{E}$ & C. teedei var. lusitanicus (Rodrigues) Bárbara and Cremades & $\mathrm{NF}$ & June 2001 & $\kappa-1$ \\
\hline $\mathrm{F}$ & C. teedei var. lusitanicus (Rodrigues) Bárbara and Cremades & FG & June 2001 & $\kappa-1$ \\
\hline G & A. devoniensis (Greville) P.C. Silva and DeCew & $\mathrm{G}$ & July 2001 & $i(\kappa)$ \\
\hline $\mathrm{H}$ & A. devoniensis (Greville) P.C. Silva and DeCew & NF & August 2001 & $1(\kappa)$ \\
\hline I & G. crenulatus (Turner) J. Agardh & $\mathrm{TB}$ & April 2002 & $1(\kappa)$ \\
\hline $\mathrm{J}$ & A. devoniensis (Greville) P.C. Silva and DeCew & G & December 2001 & $1(\kappa)$ \\
\hline $\mathrm{L}$ & C. jubata (Goodenough and Woodward) Kützing & NF & March 2001 & 1 \\
\hline M & C. jubata (Goodenough and Woodward) Kützing & $\mathrm{T}$ & May 2001 & 1 \\
\hline $\mathrm{N}$ & C. jubata (Goodenough and Woodward) Kützing & FG & April 2001 & 1 \\
\hline $\mathrm{O}$ & G. crenulatus (Turner) J. Agardh & $\mathrm{TB}$ & November 2001 & 1 \\
\hline Q & C. crispus Stackhouse & $\mathrm{T}$ & May 2001 & $\lambda$ \\
\hline $\mathrm{R}$ & G. pistillata (S.G. Gmelin) Stackhouse & $\mathrm{H}$ & February 2002 & $\lambda$ \\
\hline $\mathrm{S}$ & G. pistillata (S.G. Gmelin) Stackhouse & $\mathrm{T}$ & April 2002 & $\lambda$ \\
\hline $\mathrm{T}$ & Chondrachantus acicularis (Roth) Fredericq & $\mathrm{T}$ & August 2001 & $\xi$ \\
\hline $\mathrm{U}$ & C. teedei var. lusitanicus (Rodrigues) Bárbara and Cremades & $\mathrm{T}$ & June 2001 & $\xi$ \\
\hline
\end{tabular}

T, tetrasporophytes; FG, female gametophytes; G, gametophytes; NF, non-fertile thalli; TB, tetrasporoblastic thalli; H, heterosporic thalli.

diamond ATR system, with no need for sample preparation. All spectra are the average of two counts, with 128 scans each and a resolution of $2 \mathrm{~cm}^{-1}$.

The room temperature FT-Raman spectra were recorded on a RFS-100 Bruker FT-spectrometer using a Nd:YAG laser with excitation wavelength of $1064 \mathrm{~nm}$. Each spectrum is the averaging of two repeated measurements of 150 scans each and $2 \mathrm{~cm}^{-1}$ resolution.

${ }^{13} \mathrm{C}$ NMR spectra were recorded on a Varian Unity 500 spectrometer at $125.69 \mathrm{MHz}$. Samples $(15 / 20 \mathrm{mg}$ $\mathrm{ml}^{-1}$ ) were dissolved in $\mathrm{D}_{2} \mathrm{O}$ and spectra recorded at $80{ }^{\circ} \mathrm{C}, 10000$ accumulations, pulse $15 \mu \mathrm{s}$, acquisition time $3 \mathrm{~s}$ and relaxation delay $5 \mathrm{~s}$. The chemical shifts (ppm) were measured in relation to the reference acid sodium salt (TMSPSA).

\section{Results}

Information about sampling dates, reproductive stages and carrageenan type of the analysed algal species is given in Table 1 .

The FTIR spectra of the C. crispus, M. stellatus, Gigartina pistillata (Gigartinaceaea) gametophytes samples and non-fertile thalli samples of C. crispus (Fig. 1) present strong absorption bands in $930 \mathrm{~cm}^{-1}$ region (3,6-anhydro-D-galactose) and in the $845 \mathrm{~cm}^{-1}$ region (D-galactose-4-sulphate), typical of $\kappa$-carrageenan. They present lower absorbance in the $805 \mathrm{~cm}^{-1}$ region $(3,6-$ anhydro-D-galactose-2-sulphate), which indicates a presence of low quantities of 1 -carrageenan $[5,6]$. The ratio between 805 and $845 \mathrm{~cm}^{-1}$ absorption bands was calculated [5,7] and used as parameter to determine the degree of the $\kappa-1$ hybridisation (Figs. 1, 3 and 4).

In the Chondracanthus teedei var. lusitanicus (Gigartinaceae) gametophytes and non-fertile thalli samples, the FTIR spectra (Fig. 2) present strong absorption in 930 and $845 \mathrm{~cm}^{-1}$ and medium absorption in $805 \mathrm{~cm}^{-1}$ bands. The presence of three picks in the anomeric zone, in ${ }^{13} \mathrm{C}$ NMR spectra (Table 2), is typical of $\kappa-1$ hybrid carrageenan [8].

For the species Ahnfeltiopsis devoniensis (Phyllophoraceae), Gymnogongrus crenulatus (Phyllophoraceae) and Calliblepharis jubata (Solieriaceae), FTIR spectra show absorption bands at 930, 845 and $805 \mathrm{~cm}^{-1}$, which represent the characteristic triplet for 1-carrageenan (Figs. 3 and 4). However, the peak ratio (805/845 $\mathrm{cm}^{-1}$ ) is lower in A. devoniensis and $G$. crenulatus than the presented by the C. jubata and E. denticulatum (sample from Sigma, C-4014).

In the C. crispus and G. pistillata tetrasporic samples the FTIR spectra (Fig. 5) present broad absorption bands in $820-830 \mathrm{~cm}^{-1}$ region, characteristic of the $\lambda$ carrageenan [5,6]. The FT-Raman spectra of these samples present a broad peak in $820 \mathrm{~cm}^{-1}$ (Fig. 6), which confirm the presence of $\lambda$-carrageenan.

The FTIR spectra of tetrasporic samples of Chondracanthus species show sharper peaks at $830 \mathrm{~cm}^{-1}$, but little absorption at $820 \mathrm{~cm}^{-1}$, which indicates the presence of $\xi$-carrageenan (Fig. 5). The presence of 815 and $850 \mathrm{~cm}^{-1}$ in FT-Raman spectra confirms the presence of the mentioned carrageenan (Fig. 7). 


\section{Discussion}

In this study the $\kappa$-family carrageenans $(\kappa$ and $\kappa-1$ hybrids) are produced by the gametophytes and the nonfertile thalli of the species belonging to the Gigartina-

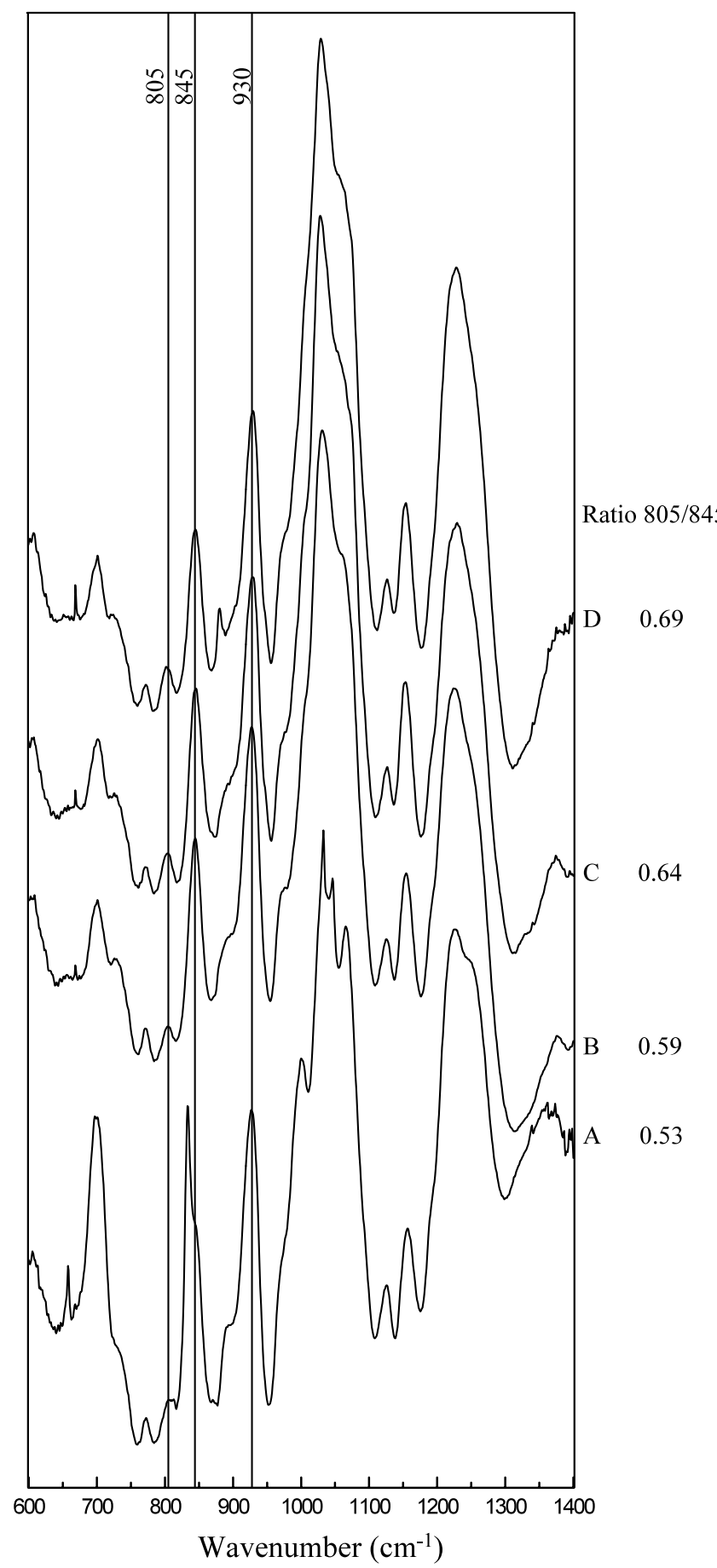

Fig. 1. FTIR spectra of alkali treated carrageenan: (A) C. crispus (non-fertile thalli), (B) C. crispus (female gametophytes), (C) $M$. stellatus (gametophytes), (D) G. pistillata (female gametophytes).

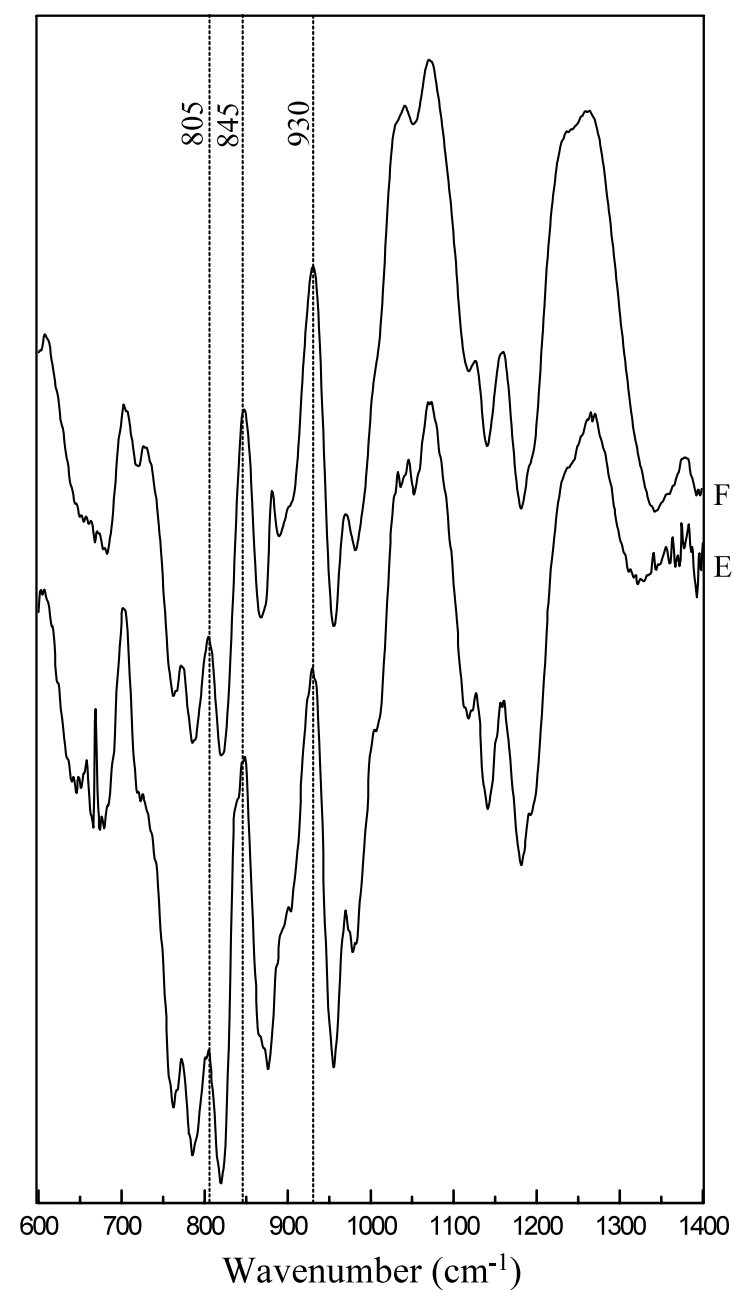

Fig. 2. FTIR spectra of alkali treated carrageenan: (E) C. teedei var. lusitanicus (non-fertile thalli), (F) C. teedei var. lusitanicus (female gametophytes).

ceae and Petrocelidaceae families, while the $\lambda$-family carrageenans ( $\lambda$ and $\xi$ carrageenans) are produced by the tetrasporic stages (Table 1).

Table 2

${ }^{13} \mathrm{C}$ NMR chemical shifts for $C$. teedei var. lusitanicus carrageenans: E (non-fertile thalli) and $\mathrm{F}$ (female gametophytes)

\begin{tabular}{lll}
\hline $\mathrm{E}$ & $\mathrm{F}$ & Assignment \\
\hline 104.7 & 104.7 & $\mathrm{IG}_{1} ; \kappa \mathrm{G}_{1}$ \\
97.6 & 97.5 & $\mathrm{\kappa A}_{1}$ \\
94.3 & 94.3 & $\mathrm{iA}_{1}$ \\
81.4 & 81.2 & $\mathrm{\kappa A}_{3} ; \kappa \mathrm{G}_{3}$ \\
80.6 & 80.6 & $\mathrm{IA}_{4} ; \kappa \mathrm{A}_{4}$ \\
79.0 & 79.1 & $\mathrm{IG}_{3} ; \kappa \mathrm{A}_{5}$ \\
77.0 & 77.0 & $\mathrm{IG}_{5} ; \kappa \mathrm{G}_{5} ; \mathrm{iA}_{2}$ \\
76.4 & 76.3 & $\mathrm{\kappa G}_{4}$ \\
74.3 & 74.4 & $\mathrm{IG}_{4}$ \\
72.1 & 71.9 & $\mathrm{IA}_{6} ; \kappa \mathrm{G}_{2} ; \kappa \mathrm{A}_{2}$ \\
63.5 & 63.5 & $\mathrm{IG}_{6} ; \kappa \mathrm{G}_{6}$ \\
\hline
\end{tabular}

$\mathrm{G}$, galactose; A, anhydrogalactose. 


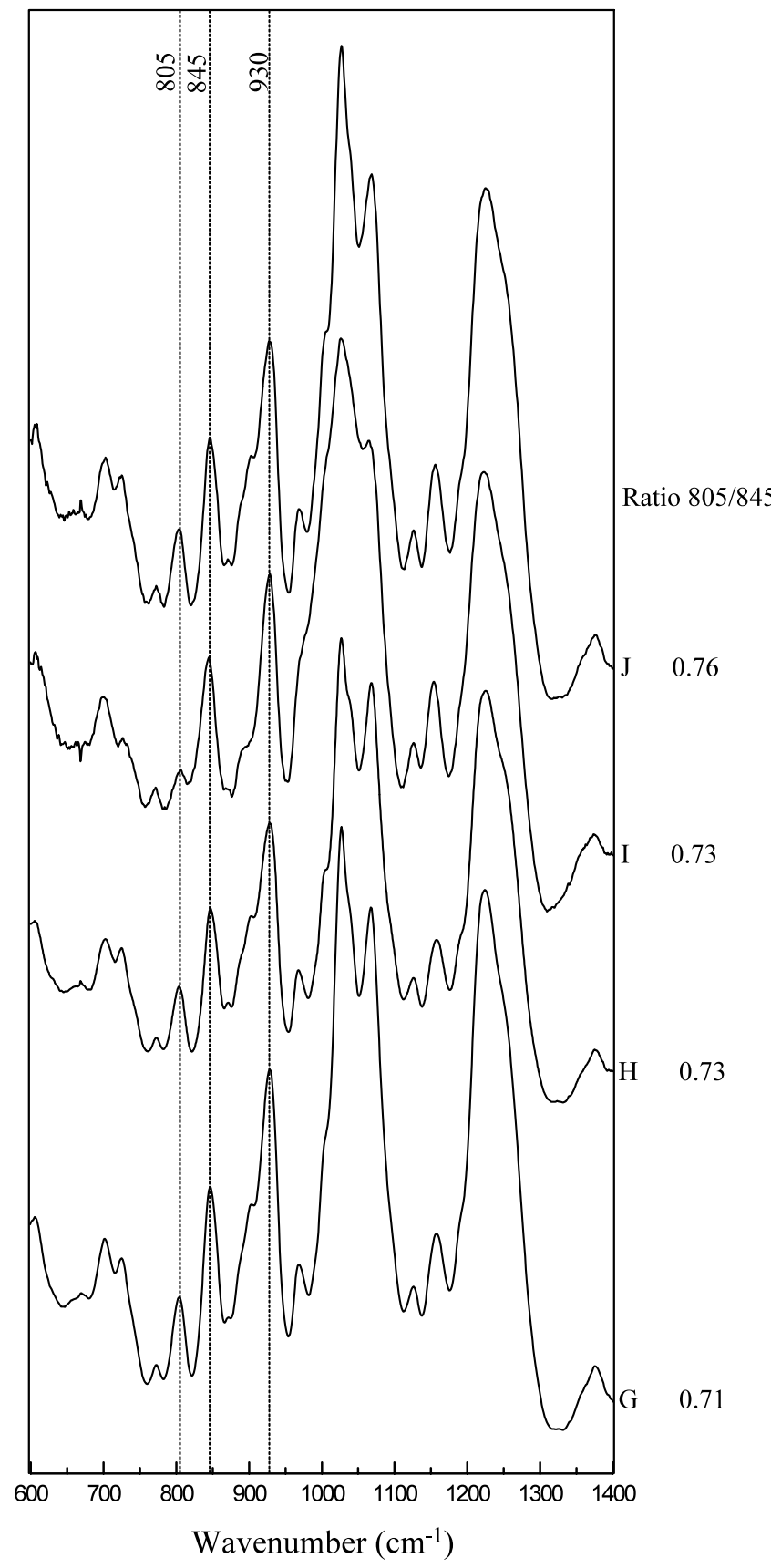

Fig. 3. FTIR spectra of alkali treated carrageenan: $(\mathrm{G})$ A. devoniensis (gametophytes), (H) A. devoniensis (non-fertile thalli), (I) G. crenulatus (tetrasporoblastic thalli) (J) A. devoniensis (gametophytes).



Fig. 4. FTIR spectra of alkali treated carrageenan: (L) C. jubata (nonfertile thalli), (M) C. jubata (tetrasporophytes), (N) C. jubata (female gametophytes), (O) G. crenulatus (tetrasproblastic thalli), (P) $E$. denticulatum (sample from Sigma, C-4014).

and autumn/winter. The ratio $805 / 845$ (Figs. 3 and 4) in the autumn/winter samples is greater than that was found in spring/summer ones, indicating a bigger percentage of -type. However, for definitive conclusions, it is necessary to analyse more samples by ${ }^{13} \mathrm{C}$ NMR. 




Fig. 5. FTIR spectra of alkali treated carrageenan: (Q) C. crispus (tetrasporophytes), (R) G. pistillata (heterosporic thalli), (S) G. pistillata (tetrasporophytes), (T) C. acicularis (tetrasporophytes), (U) C. teedei var. lusitanicus (tetrasporophytes).

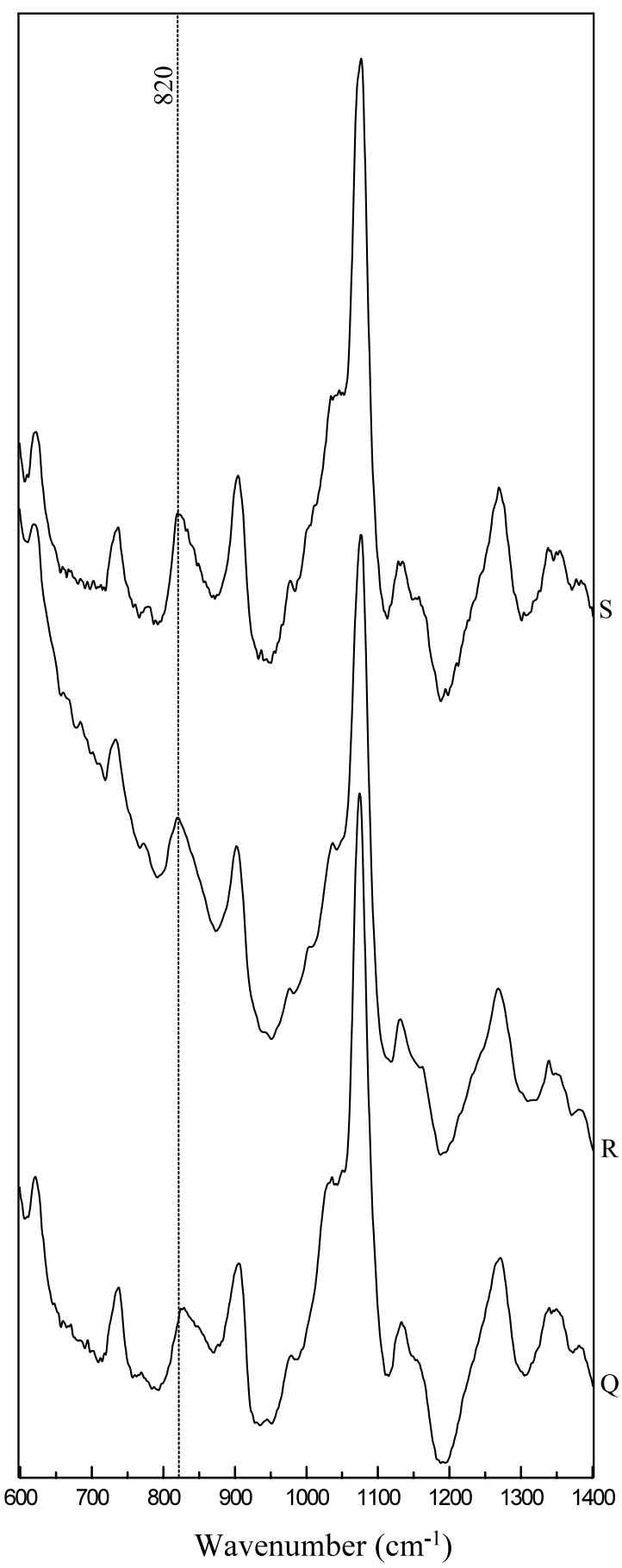

Fig. 6. FT-Raman spectra of alkali treated carrageenan: (Q) C. crispus (tetrasporophytes), (R) G. pistillata (heterosporic thalli), (S) G. pistillata (tetrasporophytes).

\section{Conclusions}

This study shows that several carrageenophytes of the Portuguese coast could be used for industrial applications. So, $\kappa$ and $\lambda$ fractions can be provided, respec- 


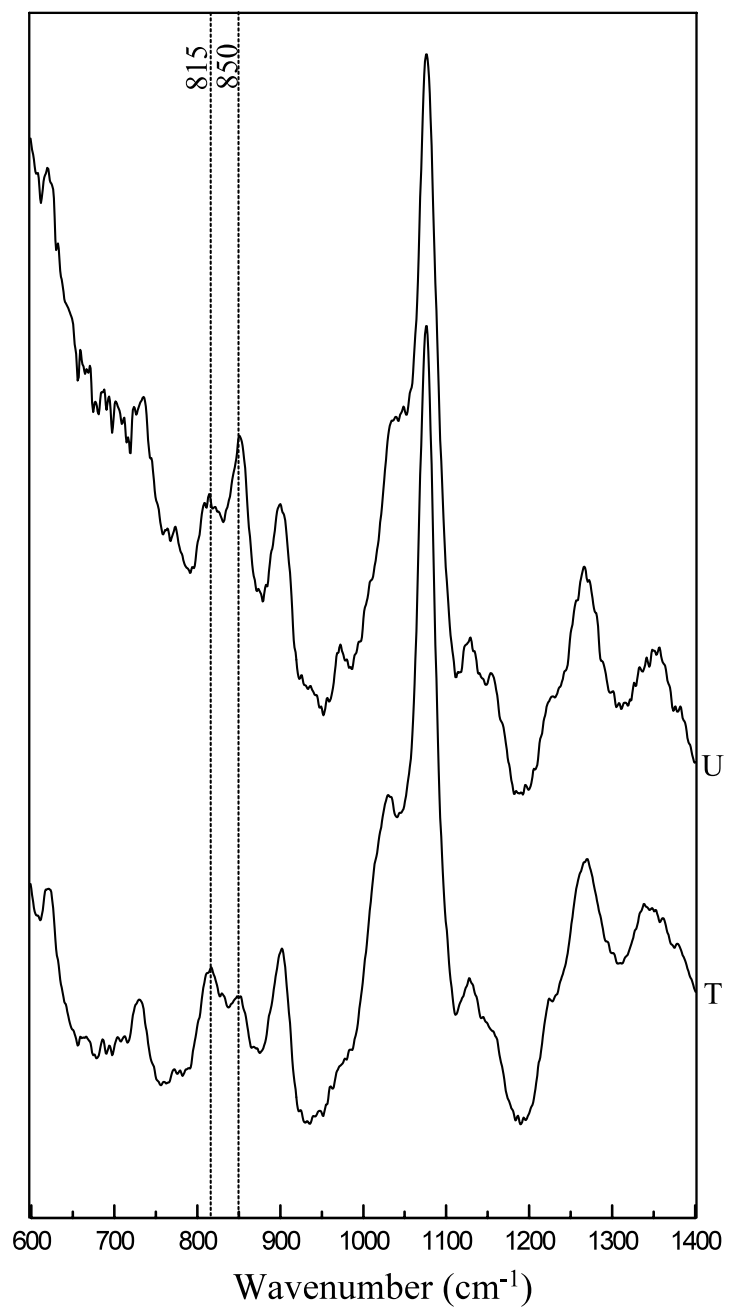

Fig. 7. FT-Raman spectra of alkali treated carrageenan: (T) $C$. acicularis (tetrasporophytes), (U) C. teedei var. lusitanicus (tetrasporophytes). tively, by gametophytes and tetrasporophytes of Petrocelidaceae and Gigartinaceae species. The 1 fraction could be obtained from the Phyllophoraceae and Cystocloniaceae species, in substitution of traditional 1-carrageenan sources (E. denticulatum).

The presence of significant populations of $C$. teedei var. lusitanicus, producing $\kappa-1$ hybrid carrageenan will be able to constitute an important source of hybrid carrageenans, this being important regarding the increasing search of these hybrid phycocolloid in food industry of milk derivatives.

\section{Acknowledgements}

We are grateful to Dr M. Caldeira and Dr A.M. Amado for help in spectroscopic analysis and A. Sousa and H. Coelho for help in seaweeds sampling.

\section{References}

[1] McLachlan J. Plant Soil 1985;89:137-57.

[2] Craigie JS. In: Cole KM, Sheath RG, editors. Biology of the red algae. Cambridge: Cambridge University Press, 1990:226-57.

[3] Cosson J, Deslandes E, Braud JP. Hydrobiologia 1990;204205:539-44.

[4] Pereira L, Mesquita J. Algal biotechnology: a sea of opportunities. Abstracts - the first congress of the international society for applied phycology. Almería, Spain, 2002. p. 172.

[5] McCandless EL, West JA, Guiry MD. Biochem Syst Ecol 1983;11:175-82.

[6] Correa-Díaz F, Aguilar-Rosas R, Aguilar-Rosa LE. Hydrobiologia 1990;204-205:609-14.

[7] Rochas C, Lahaye M, Yaphe W. Bot Mar 1986;29:335-40.

[8] Zinoun M, Cosson J, Deslandes E. J Appl Phycol 1993;5:23-8. 